\title{
Correction to: Spatial analysis of production-living-ecological functions and zoning method under symbiosis theory of Henan, China
}

\author{
Xiaotong Xie ${ }^{1,2,3} \cdot$ Xiaoshun $\mathrm{Li}^{1,2,3} \cdot$ Huiping Fan ${ }^{1,2,3} \cdot$ Weikang $\mathrm{He}^{1,2,3}$ \\ Published online: 9 August 2021 \\ (C) Springer-Verlag GmbH Germany, part of Springer Nature 2021
}

Correction to: Environmental Science and Pollution Research https://doi.org/10.1007/s11356-021-15165-x

The correct Table 4 is presented in this paper.

The original article has been corrected.

Publisher's note Springer Nature remains neutral with regard to jurisdictional claims in published maps and institutional affiliations.

The online version of the original article can be found at https://doi.org/ 10.1007/s11356-021-15165-x

Xiaoshun Li

1xsh1983@163.com

1 Jiangsu Key Laboratory of Resources and Environmental Information Engineering, China University of Mining and Technology, Xuzhou 221116, China

2 Research Center for Transition Development and Rural Revitalization of Resource-Based Cities in China, China University of Mining and Technology, Xuzhou 221116, China

3 Observation and Research Station of Jiangsu Jiawang Resource Exhausted Mining Area Land Restoration and Ecological Succession, Ministry of Education, Xuzhou 221116, China 